\title{
Extraction of Flavonoids from Bitter Melon
}

\author{
Sing Pei Tan ${ }^{1 *}$, Sophie E. Parks ${ }^{1,2}$, Costas E. Stathopoulos ${ }^{1}$, Paul D. Roach ${ }^{1}$ \\ ${ }^{1}$ School of Environmental and Life Sciences, University of Newcastle, Ourimbah, Australia; ${ }^{2}$ Central Coast Primary Industries Cen- \\ tre, NSW Department of Primary Industries, Ourimbah, Australia. \\ Email: * $\underline{\text { SingPei.Tan@newcastle.edu.au }}$
}

Received January $2^{\text {nd }}, 2014$; revised February $2^{\text {nd }}, 2014$; accepted February $10^{\text {th }}, 2014$

Copyright (C) 2014 Sing Pei Tan et al. This is an open access article distributed under the Creative Commons Attribution License, which permits unrestricted use, distribution, and reproduction in any medium, provided the original work is properly cited. In accordance of the Creative Commons Attribution License all Copyrights @ 2014 are reserved for SCIRP and the owner of the intellectual property Sing Pei Tan et al. All Copyright (C) 2014 are guarded by law and by SCIRP as a guardian.

\section{ABSTRACT}

Bitter melon, Momordica charantia L, is a popular traditional medicinal fruit in tropical and subtropical countries. It has been linked with therapeutic effects, some of which are likely due to its flavonoids. To determine its total flavonoid content (TFC) and to prepare extracts for use as nutritional supplements or ingredients for nutraceutical functional foods, various solvents have been used, including water, which is the preferred solvent because it is inexpensive, safe and environmentally friendly. The study aimed to extract bitter melon, using five solvents (ethanol, methanol, n-butanol, acetone and water) before and after the optimal conditions for water were determined in terms of extraction temperature, time, ratio of water to bitter melon $(\mathrm{mL} / \mathrm{g})$ and number of times the same material was extracted. The TFC of six varieties of bitter melon was also determined. Acetone was the best of the five solvents for extracting flavonoids from the Moonlight variety (23.2 mg Rutin Equivalents (RE)/g). Even after increasing the extraction by $88 \%(1.24 \mathrm{vs} 0.66 \mathrm{mg} \mathrm{RE} / \mathrm{g})$ using optimised conditions for the aqueous extraction (two extractions at $40^{\circ} \mathrm{C}$ for $15 \mathrm{~min}$ at a ratio of $100: 1 \mathrm{~mL} / \mathrm{g}$ of bitter melon powder), the flavonoids extracted from the Moonlight variety using water was very little $(5.4 \%)$ compared to acetone. Furthermore, using acetone, it was shown that the Moonlight variety (23.2 $\mathrm{mg} \mathrm{RE} / \mathrm{g})$ bought at a local market had higher levels of flavonoids than the greenhouse-grown Jade (15.3 mg RE/g), Niddhi (16.9 mg RE/g), Indra (15.0 mg RE/ g), Hanuman (3.9 mg RE/g) and White (6.9 mg RE/g) varieties. Therefore, acetone was the best solvent for extracting flavonoids from bitter melon and the aqueous extraction could only be improved to extract $5.4 \%$ of the flavonoids extracted with acetone from the Moonlight variety, which had the highest TFC of the six varieties of bitter melon.

\section{KEYWORDS}

Flavonoids; Bitter Melon; Acetone; Aqueous; Extractions

\section{Introduction}

Bitter melon, Momordica charantia L. is a member of the Cucurbitaceae family. The latin name "Momordica" means 'to bite' and refers to the leaves of the bitter melon plants, which have jagged edges and look like they have been bitten [1]. It is also referred to by different names around the world: balsam pear (English), Karella (Hindi or Urdu), Nigauri or Goya (Japanese), Ku gua (Madarin), Ko guai (Taiwanese), Kho qua (Vietnamese), Ampalaya (Philippines) and Assorossie (French). Generally, the bitter melon fruit has an oblong cucumber-like

*Corresponding author. shape, ranging from 9 to $60 \mathrm{~cm}$ long, but in contrast to cucumbers, it has a very warty-looking exterior [2].

Bitter melon is widely cultivated in tropical and subtropical countries, where it is a popular traditional medicinal fruit. In the scientific literature, it has been linked with a wide range of therapeutic effects, including anticancer [3], anti-viral [4], anti-inflammatory [5], hypolipidaemic [6], hypocholesterolaemic [6], immuno-modulatory [7] and anti-diabetic [8] properties. Studies have reported that different varieties of bitter melon may differ in their content of bioactive compounds $[9,10]$. However, some of the proposed therapeutic effects have been in part attributed to its content of flavonoids [7,8,11]. 
Flavonoids are polyphenolic compounds with a nuclear structure of $\mathrm{C}_{6}-\mathrm{C}_{3}-\mathrm{C}_{6}$, which is comprised of two benzene rings linked to a pyrene ring containing oxygen [12]. Flavonoids occur naturally in plants either linked to sugars (glycosides) or without the sugars (aglycones). Flavonoid aglycones are usually extracted with less polar solvents, such as benzene, chloroform and diethyl ether [13] while flavonoid glycosides are commonly extracted with more polar solvents, such as acetone, butanol, methanol and ethanol [14-16]. Ethanol [11,17], water [11] and methanol [18] have been used for extracting flavonoids and other bioactive compounds from bitter melon. However, studies on the use of different solvents, including water and less polar organic solvents, for the extraction of flavonoids from different bitter melon varieties are still limited. For example, the ratio of flavonoid aglycones to glycosides may differ between varieties and thereby lead to different extraction efficiencies, depending on the type of solvent used [13-16].

Recently, the use of less polar organic solvents for extracting bioactive components and other compounds from plant materials has become increasingly unpopular because these solvents have significant safety, toxicity and environmental issues associated with them and consumers are increasingly concerned about the impact on their health of such practices. Therefore, water (a polar solvent) is always preferable as an extraction solvent because it is non-toxic, environmentally friendly and inexpensive compared with organic solvents [19].

Importantly, water has been used to extract flavonoids from bitter melon [11]. However, if water is to be the solvent of choice, the optimal conditions for the aqueous extraction of flavonoids from bitter melon need to be determined. The aqueous extraction of bioactive compounds from plant matrices is known to be dependent on several extraction parameters $[12,20]$. For example, the temperature and length (time) of the extraction, the ratio of the water to the plant material and how many times the same material is extracted can have significant impacts on the extraction of bioactive compounds from plant materials [19-21]. Furthermore, in the case of flavonoids, because they occur as aglycones and glycosides, the extraction efficiency obtained with optimal aqueous conditions also needs to be compared with that of less polar solvents.

Therefore, the present study aimed to determine the optimal aqueous conditions for extracting flavonoids from bitter melon, in terms of extraction temperature and time, the ratio of water to bitter melon $(\mathrm{mL} / \mathrm{g})$ and the number of times the same material was extracted. For comparison, extractions with less polar solvents, methanol, ethanol, n-butanol and acetone, were also done. The flavonoid content of six varieties of bitter melon was also determined.

\section{Materials and Methods}

\subsection{Plant Materials}

Six varieties, Moonlight, Hanuman, White, Jade, Niddhi and Indra were analysed in the present study. The Moonlight variety was purchased from the Sydney Markets (Sydney, NSW, Australia) and used for most of the studies because high amounts were available. The other five varieties were grown in greenhouses at the NSW Department of Primary Industries Research Station in Narara, NSW, Australia $\left(151^{\circ} 19^{\prime} \mathrm{E}, 33^{\circ} 23^{\prime} \mathrm{S}\right)$ in January 2013.

The bitter melons were immediately stored at $-20^{\circ} \mathrm{C}$ until used. The frozen bitter melons were cut into slices ( $\sim 1$ to $2 \mathrm{~mm}$ ), cooled further in liquid nitrogen and then dried using a FD3 freeze dryer (Rietschle Thomas, Seven Hills, NSW, Australia). The freeze-dried bitter melon slices were ground using a commercial Waring blender (John Morris Scientific, Chatswood, NSW, Australia). Then, the powder was passed through a 1 mm EFL 2000 stainless steel sieve (Endecotts, London, England). The ground freeze-dried bitter melon powder was then sealed in resealable storage plastic bags (Bi-Lo Supermarket, Lisarow, NSW, Australia) and stored at $-20^{\circ} \mathrm{C}$ until used.

\subsection{Chemicals}

Methanol and acetone were obtained from Merck (Kilsyth, Vic, Australia). Ethanol was purchased from Fronine (Taren Point, NSW, Australia) and the n-Butanol was obtained from Swift Australia Chemical Supplier (Mulgrave, Vic, Australia). Sodium nitrite, aluminium chloride, sodium hydroxide and rutin were purchased from Sigma-Aldrich (Castle Hill, NSW, Australia).

\subsection{Extraction of Bitter Melons}

\subsubsection{Extraction with Five Solvents}

The freeze-dried powder from the Moonlight variety was used to compare the extraction of flavonoids using five solvents: methanol, ethanol, n-butanol, acetone and water. Moonlight powder samples (1 g) were added to $100 \mathrm{~mL}$ of each solvent and incubated for $1 \mathrm{~h}$ at different temperatures using a shaking water bath (Ratek Instruments, Boronia, Vic, Australia). The extraction temperatures were set below the boiling point of each solvent: $80^{\circ} \mathrm{C}$ for ethanol, n-butanol and water and $50^{\circ} \mathrm{C}$ and $60^{\circ} \mathrm{C}$ for acetone and methanol, respectively.

After extraction, the samples were allowed to cool down and settle for $10 \mathrm{~min}$ on ice. The extracts were then centrifuged at $4350 \times \mathrm{g}$ for $10 \mathrm{~min}$ at $10^{\circ} \mathrm{C}$ using a Beckman J2-MC Centrifuge and a JA-20 rotor (Beckman Instruments Inc, Palo Alto, CA, USA) and the super- 
natant from each sample was filtered through a $0.45 \mu \mathrm{m}$ syringe filter (Phenomenex, Pennants Hills, NSW, Australia).

\subsubsection{Optimising Aqueous Extraction Conditions}

To determine the optimal conditions for the aqueous extraction of the flavonoids from bitter melon, four parameters were studied: temperature $\left(5^{\circ} \mathrm{C}, 10^{\circ} \mathrm{C}, 20^{\circ} \mathrm{C}\right.$, $30^{\circ} \mathrm{C}, 40^{\circ} \mathrm{C}, 50^{\circ} \mathrm{C}, 60^{\circ} \mathrm{C}, 70^{\circ} \mathrm{C}, 80^{\circ} \mathrm{C}$, and $90^{\circ} \mathrm{C}$ ), time (5, $10,15,20,25,30,40,50$ and $60 \mathrm{~min})$, ratio of water to bitter melon powder (10, 20, 25, 30, 40, 50, 100 and 120 $\mathrm{mL} / \mathrm{g}$ of powder) and the number of times the same powder sample was extracted (1, 2 and 3 times).

Firstly, $1 \mathrm{~g}$ of freeze-dried Moonlight powder was extracted with $100 \mathrm{~mL}$ of deionised water at the different temperatures for $1 \mathrm{~h}$ using the shaking water bath. The optimal temperature $\left(40^{\circ} \mathrm{C}\right)$ was then used for the experiment to determine the optimal extraction time. Briefly, $1 \mathrm{~g}$ of freeze-dried powder was extracted with $100 \mathrm{~mL}$ of deionised water at $40^{\circ} \mathrm{C}$ for the different lengths of extraction time. The optimal time (15 min) and temperature $\left(40^{\circ} \mathrm{C}\right)$ were then used to determine the optimal water-to-powder ratio $(\mathrm{mL} / \mathrm{g})$; again, $1 \mathrm{~g}$ of freeze-dried powder was extracted using the different volumes of deionised water. Finally, to determine the impact of the number of times the same sample was extracted, $1 \mathrm{~g}$ of the freeze-dried powder was extracted with $100 \mathrm{~mL}$ (the optimal ratio) of deionised water once, twice or three times at $40^{\circ} \mathrm{C}$ for $15 \mathrm{~min}$. All extracts were then centrifuged and filtered as described in Section 2.3.1.

\subsubsection{Extraction of the Six Varieties of Bitter Melons}

To compare the six varieties of bitter melon, $1 \mathrm{~g}$ of each freeze-dried powder from the Moonlight, Hanuman, White, Jade, Niddhi and Indra varieties were extracted with $100 \mathrm{~mL}$ of acetone at $50^{\circ} \mathrm{C}$ using the shaking water bath. The extracts were then centrifuged and filtered as described in Section 2.3.1.

\subsection{Total Flavonoid Content}

The total flavonoid content (TFC) of the bitter melon extracts was determined as described by Wu and Ng [11]. Briefly, $0.5 \mathrm{~mL}$ of diluted sample was mixed with $2 \mathrm{~mL}$ of deionised water followed by the addition of $150 \mu \mathrm{L}$ of $5 \%(\mathrm{w} / \mathrm{v})$ sodium nitrite solution. After $6 \mathrm{~min}, 150 \mu \mathrm{L}$ of $10 \%(\mathrm{w} / \mathrm{v})$ aluminum chloride was added and the mixture was incubated for another $6 \mathrm{~min}$. Then, $2 \mathrm{~mL}$ of $4 \%(\mathrm{w} / \mathrm{v})$ sodium hydroxide was added and the solution was immediately made up to $5 \mathrm{~mL}$ with deionised water, mixed thoroughly and placed in the dark at room temperature for $15 \mathrm{~min}$. The absorption of the solution was measured at $510 \mathrm{~nm}$ against a reagent blank. Rutin was used as a standard and the TFC was expressed as mg of Rutin Equivalents (RE) per $g$ of bitter melon powder on a dry basis (mg RE/g).

\subsection{Statistical Analysis}

Results were expressed as mean values with standard deviations (mean \pm SD). Significant differences between mean values in the different experiments were tested using the one-way analysis of variance (ANOVA) and the Bonferroni post-hoc test using a 5\% significance level $(\mathrm{P}<0.05)$.

\section{Results and Discussion}

\subsection{Extraction of Flavonoids with Five Solvents}

The solubility of flavonoids is highly correlated with their chemical structures and the nature of the extraction solvent [22]. Of the different solvents studied (Figure 1), acetone (23.17 mg RE/g) was by far the best solvent for extracting flavonoids from the Moonlight bitter melon variety, followed by methanol (7.67 mg RE/g), ethanol (5.38 mg RE/g), n-butanol (1.81 mg RE/g) and water (0.66 mg RE/g).

Our findings were in agreement with a study by Ferreira \& Pinho [23], which found that the flavonoid, hesperetin, was more soluble in acetone than in methanol, followed by ethanol, ethyl acetate and acetonitrile. A similar trend was reported by Wu et al. [24], who found that the flavonoid, genistein, was more soluble in methanol and ethanol than in propan-2-ol, followed by butanol and water [24]. Furthermore, Tommasini et al. [25] found that the solubility of flavonoids was very low in polar solvents, especially in water. However, a study by Wu and Ng [11] demonstrated that the bitter melon aqueous extract had a higher TFC than the ethanol extract.

\subsection{Optimising Aqueous Extraction Conditions}

The study by $\mathrm{Wu}$ and $\mathrm{Ng}$ [11] suggests that some of the flavonoids in bitter melon are soluble in water. Therefore, because water is the safest, cheapest and most environmentally-friendly solvent for natural product extractions, it was important to determine the optimal conditions for extracting flavonoids from bitter melon using water.

\subsubsection{Optimal Extraction Temperature}

Several studies have indicated that temperature is one of the most important parameters that can affect the extraction efficiency of flavonoids from plant materials [19, $21,26]$. As a consequence, the influence of temperature on the extraction of flavonoids from bitter melon was determined using the Moonlight variety. The results showed that temperature had a significant impact on the TFC (Figure 2).

The TFC of the aqueous extracts significantly increased by $46 \%$ when the temperature was increased 


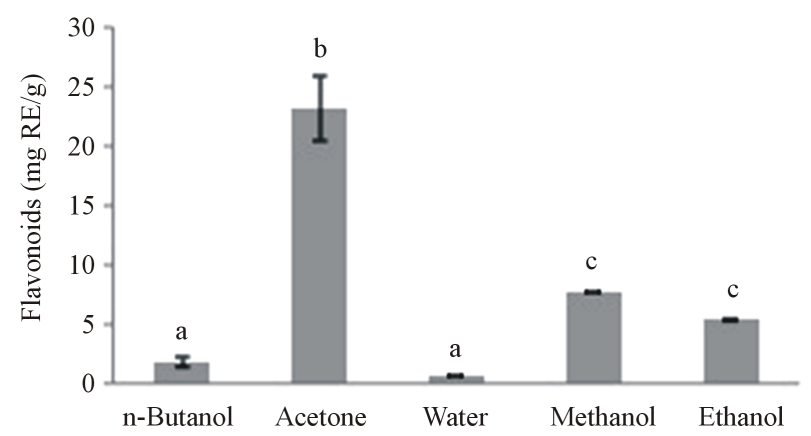

Figure 1. The extraction of flavonoids with five solvents. Moonlight bitter melon powder (1 g) was extracted with 100 $\mathrm{mL}$ of each solvent for $1 \mathrm{~h}$ at $80^{\circ} \mathrm{C}$ for ethanol, n-butanol and water and at $50^{\circ} \mathrm{C}$ and $60^{\circ} \mathrm{C}$ for acetone and methanol, respectively. Values are means \pm SD of flavonoids extracted per gram of bitter melon powder and those not sharing a letter are significantly different $(P<0.05)$.

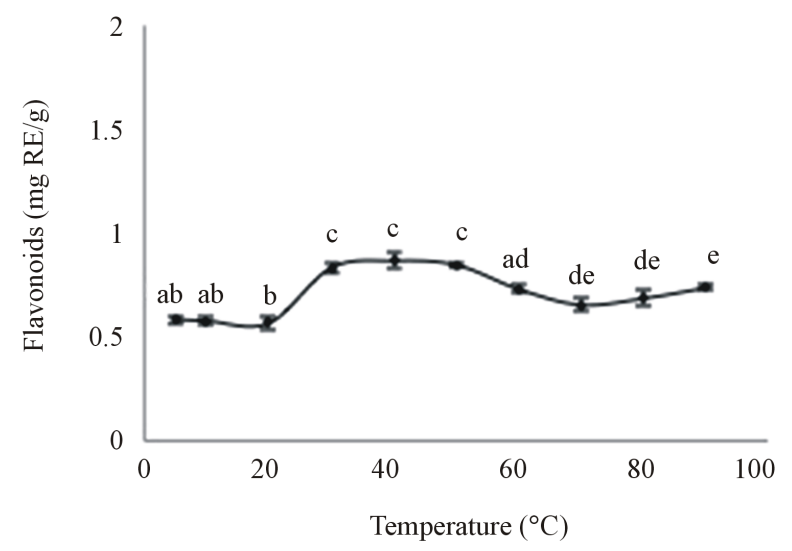

Figure 2. Effect of temperature on the aqueous extraction of flavonoids. Moonlight bitter melon powder (1 g) was extracted with $100 \mathrm{~mL}$ of water for $1 \mathrm{~h}$ at $80^{\circ} \mathrm{C}$. Values are means \pm SD of flavonoids extracted per gram of bitter melon powder and those not sharing a letter are significantly different $(\mathrm{P}<\mathbf{0 . 0 5})$.

from $5^{\circ} \mathrm{C}$ to $30^{\circ} \mathrm{C}$, where it reached a plateau, and then decreased at temperatures above $50^{\circ} \mathrm{C}$, the latter possibly due to degradation of the flavonoids [12]. Nevertheless, significantly more flavonoids were extracted at the high temperatures $\left(60^{\circ} \mathrm{C}-90^{\circ} \mathrm{C}\right)$ compared to the low temperatures $\left(5^{\circ} \mathrm{C}-20^{\circ} \mathrm{C}\right)$ (Figure 2). It is well known that heat increases the solubility and diffusion coefficients of solutes, like the flavonoids, and decreases the viscosity of the extracting solvent, especially water. High temperatures can also result in the cell wall of plant materials, such as bitter melon, becoming more permeable to solvent and therefore, the inner cell components can diffuse more easily into the solvent $[19,21]$. Since the TFC reached a plateau (Figure 3) between $30^{\circ} \mathrm{C}$ and $50^{\circ} \mathrm{C}(0.8$ - $0.9 \mathrm{mg} \mathrm{RE} / \mathrm{g}$ ), the optimal temperature was chosen to be $40^{\circ} \mathrm{C}(0.87 \mathrm{mg} \mathrm{RE} / \mathrm{g})$ and used for the subsequent optimisation experiments.

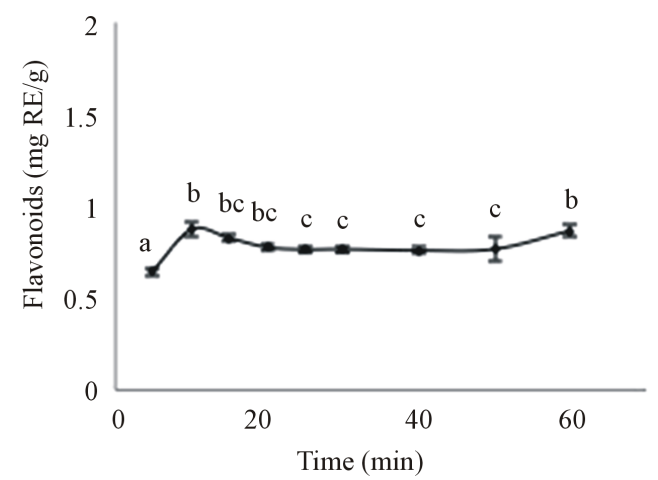

Figure 3. Effect of time on the aqueous extraction of flavonoids. Moonlight bitter melon powder $(1 \mathrm{~g})$ was extracted with $100 \mathrm{~mL}$ of water for $1 \mathrm{~h}$ at $40^{\circ} \mathrm{C}$. Values are means \pm SD of flavonoids extracted per gram of bitter melon powder and those not sharing a letter are significantly different $(\mathrm{P}<$ 0.05).

\subsubsection{Optimal Extraction Time}

The TFC of the aqueous extracts increased by $30 \%$ between 5 and 10 min of extraction time and then did not change substantially up to 60 min (Figure 3). This finding suggests that extending the extraction time up to $1 \mathrm{~h}$, as done in Figure 1, had little impact on the extraction of the bitter melon flavonoids. However, it also suggests that the flavonoids were stable and did not substantially degrade at $40^{\circ} \mathrm{C}$ throughout the $1 \mathrm{~h}$ extraction. Therefore, in the present study, the optimal extraction time was chosen to be $15 \mathrm{~min}(0.83 \mathrm{mg} \mathrm{RE} / \mathrm{g})$. In contrast, Xu et al. [27] reported that an extraction time of just over $2 \mathrm{~h}$ was optimal for the extraction of flavonoids from Fructus sophorae. However, this long extraction may have been due to their focus on only the aglycon forms of three of the flavonoids, quercetin, kaempferol and isorhamnetin and the high temperature of $90^{\circ} \mathrm{C}$ they used [27].

\subsubsection{Optimal Extraction Water-to-Powder Ratio}

Figure 4 shows that the TFC of the aqueous extracts was constant for the water-to-powder ratios of 10 to 50 but it was significantly increased by $73 \%$ at the ratios of 100 (0.83 mg RE/g) and 120 (0.84 mg RE/g) and the latter two TFC were not significantly different. Therefore, the ratio of $100: 1 \mathrm{~mL} / \mathrm{g}$ was chosen to be optimal instead of $120: 1 \mathrm{~mL} / \mathrm{g}$, in order to save on the amount of water used. The observation that the higher water-to-powder ratios resulted in the highest extraction of flavonoids from the bitter melon was not unexpected; this is known to happen because the higher ratios result in higher osmotic pressures due to steeper concentration gradients between the concentration of the solutes in the powder, such as the flavonoids, and their concentration in the solvent including at the surface of the solid material [28]. This increases the movement of the solutes from the solid material to the solvent. Therefore, the current finding was also 
consistent with other studies on the extraction of other solutes from other plant materials $[19,29]$.

\subsubsection{Optimal Number of Extractions of the Same Material}

Figure 5 shows that, compared to a single extraction (0.83 mg RE/g), two (1.24 mg RE/g) and three (1.34 mg $\mathrm{RE} / \mathrm{g}$ ) extractions of the same bitter melon material significantly increased the TFC of the aqueous extracts by $49 \%$ and $61 \%$, respectively. However, there was no significant difference between two and three sequential extractions with a total of $200 \mathrm{~mL}$ and $300 \mathrm{~mL}$ of water, respectively (Figure 5). The higher the amount of water used for an extraction the higher the cost will be, not only for the water itself but also for the energy needed to heat the water during the extraction and often for drying the extract in order to produce a powdered extract [30]. Therefore, two extractions of the same material was

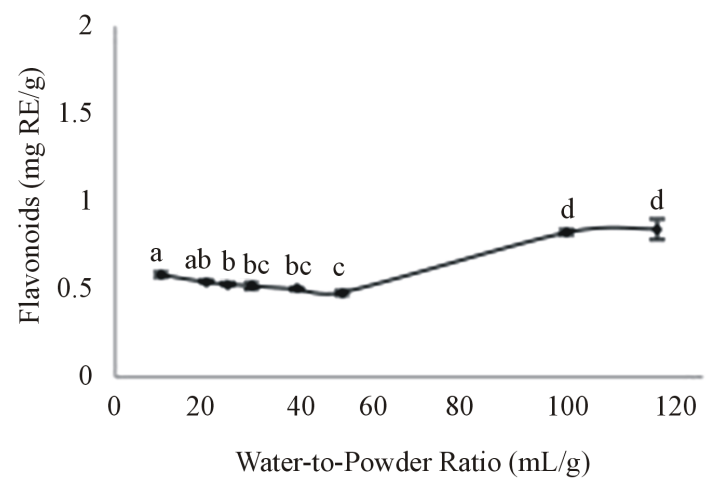

Figure 4. Effect of the water-to-powder ratio on the aqueous extraction of flavonoids. Moonlight bitter melon powder $(1 \mathrm{~g})$ was extracted with $100 \mathrm{~mL}$ of water for $15 \mathrm{~min}$ at $40^{\circ} \mathrm{C}$. Values are means \pm SD of flavonoids extracted per gram of bitter melon powder and those not sharing a letter are significantly different $(P<\mathbf{0 . 0 5})$.

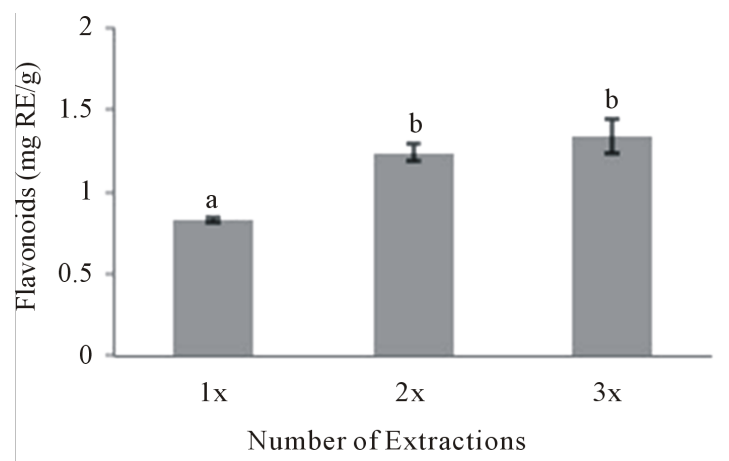

Figure 5. Effect of the number of extractions on the aqueous extraction of flavonoids. Moonlight bitter melon powder (1 g) was extracted once $(1 \times)$, twice $(2 \times)$ or three times $(3 \times)$ with $100 \mathrm{~mL}$ of water for $15 \mathrm{~min}$ at $40^{\circ} \mathrm{C}$. Values are means \pm SD of flavonoids extracted per gram of bitter melon powder and those not sharing a letter are significantly different $(\mathbf{P}<0.05)$. chosen as the optimal method for the extraction of the bitter melon flavonoids at $40^{\circ} \mathrm{C}$ for 15 min with a waterto-powder ratio of $100: 1 \mathrm{~mL} / \mathrm{g}$.

The optimal aqueous extraction conditions determined in this study resulted in $88 \%$ more flavonoids being extracted from the Moonlight bitter melon powder (1.24 mg $\mathrm{RE} / \mathrm{g}$ ) than was obtained (0.66 mg RE/g) prior to optimisation (Figure 1). However, despite this improvement, water was still not the best solvent for extracting the flavonoids from bitter melon since only $5.4 \%$ of the flavonoids (1.24 mg RE/g) were extracted using the optimal aqueous extraction conditions compared to the acetone extract (23.2 mg RE/g) (Figure 1). The use of other technologies may assist and thus increase the aqueous extraction of flavonoids from bitter melon. For example, the flavonoids extracted from bitter melon using the ethanolmodified supercritical carbon dioxide extraction at $46^{\circ} \mathrm{C}$ for $53.2 \mathrm{~min}$ at $33.4 \mathrm{MPa}$ was significantly higher than with a conventional ethanol extraction at $80^{\circ} \mathrm{C}$ for 150 $\min [17]$.

In the current study, acetone was by far the best solvent for extraction of the flavonoids from bitter melon, even after the aqueous extraction was optimised. This suggests that the flavonoids in the Moonlight variety of bitter melon, which was used to optimise the aqueous extraction, were most likely flavonoid glycosides as these are well extracted with polar solvents such as acetone [14-16]. However, clearly, not many of the flavonoid glycosides (5.4\%) in the Moonlight variety are polar enough to be effectively solubilised by water.

\subsection{Extraction of Six Varieties of Bitter Melon with Acetone}

To compare the TFC of the six varieties of bitter melon, Moonlight, Hanuman, White, Jade, Niddhi and Indra, the best solvent in the present study, acetone (Figure 1), was selected for the extraction (Figure 6). This demonstrated that the bitter melon varieties differed significantly in their levels of flavonoids with Moonlight having the highest (23.2 mg RE/g) while Hanuman (3.9 mg RE/g) and White (6.9 mg RE/g) had the lowest (Figure 6). The other three varieties, Jade (15.3 mg RE/g), Niddhi (16.9 $\mathrm{mg} \mathrm{RE} / \mathrm{g}$ ) and Indra (15.0 mg RE/g) had intermediate levels.

It is possible that different growing conditions may explain some of the differences in the amount of flavonoids extracted using acetone (Figure 6). For example, although the information was not available for the Moonlight variety bought at a local market, it is likely to have been produced under open field conditions. In contrast, the other five varieties were produced under greenhouse conditions. If they were grown under Australian field conditions, the Moonlight bitter melons are more likely to have been exposed to environmental stresses, such as 


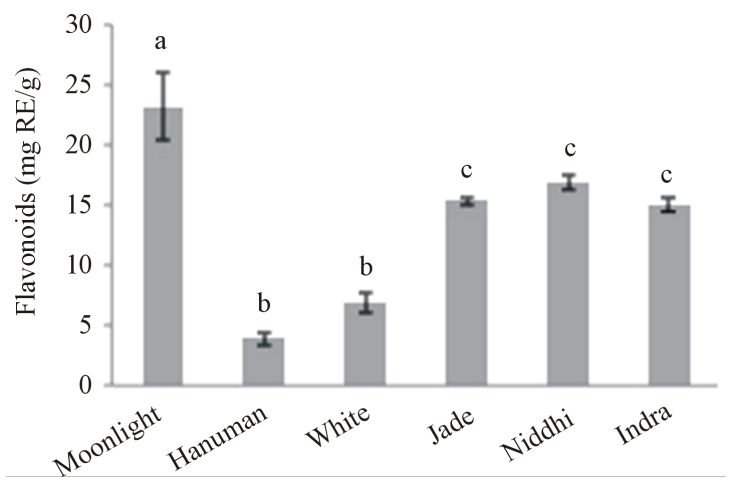

Figure 6. The extraction of flavonoids from six bitter melon varieties. Powder (1 g) from each variety was extracted with $100 \mathrm{~mL}$ of acetone at $50^{\circ} \mathrm{C}$ for $1 \mathrm{~h}$. Values are means $\pm \mathrm{SD}$ of flavonoids extracted per gram of bitter melon powder and those not sharing a letter are significantly different $(\mathrm{P}<$ 0.05).

intense sunlight and heat, and therefore have increased TFC because it is well known that fruit crops attempt to protect themselves against environmental stresses by increasing their content of bioactive compounds [9,10].

In contrast, the differences seen among the other five varieties (Figure 6) are more likely to be due to real varietal differences because they were grown under the same controlled conditions in greenhouses. Nevertheless, further studies on the bioactive compound content of bitter melon, including TFC, will have to be conducted under different growing conditions, in order to understand the effect of environmental factors on the flavonoid and other bioactive compound content of bitter melons.

The TFC of the six varieties of bitter melon fruit in this study (Figure 6) were all lower (3.9 to $23.2 \mathrm{mg} \mathrm{RE/g}$ ) than that previously measured in bitter melon leaf (56.7 mg RE/g) [31]. Even so, bitter melon fruit has been claimed to have therapeutic effects $[7,8]$, of which some could be derived from its flavonoids $[7,8,11]$. The present findings suggest that the bitter melon fruit, especially from the Moonlight variety, does have substantial amounts of flavonoids and therefore, may have medicinal properties. Furthermore, bitter melon extracts may have potential as nutritional supplements or as value-added ingredients for incorporation into nutraceutical functional foods.

\section{Conclusion}

The present study demonstrated that acetone was the best of five solvents, including water, for extracting flavonoids from bitter melon. The conditions for the aqueous extraction of flavonoids from bitter melon were optimised and determined to be two extractions of the same material at $40^{\circ} \mathrm{C}$ for $15 \mathrm{~min}$ at a ratio of $100: 1 \mathrm{~mL} / \mathrm{g}$ of bitter melon powder. However, after optimisation, the content of flavonoids in the aqueous extract was still much less (only 5.4\%) than in the acetone extract. Furthermore, using acetone, it was shown that the Moonlight variety bought at a local market had a higher content of flavonoids compared to five other greenhouse-grown bitter melon varieties.

\section{Acknowledgements}

The authors acknowledge the University of Newcastle, Australia, for the financial support through a PhD scholarship for S. P. Tan.

\section{REFERENCES}

[1] J. K. Grover and S. P. Yadav, "Pharmacological Actions and Potential Uses of Momordica Charantia: A Review," Journal of Ethnopharmacology, Vol. 93, No. 1, 2004, pp. 123-132. http://dx.doi.org/10.1016/j.jep.2004.03.035

[2] E. A. Lucas, G. G. Dumancas, B. J. Smith, S. L. Clarke and B. H. Arjmandi, "Health Benefits of Bitter Melon (Momordica charantia),” In: W. Ronald Ross and R. P. Victor, Eds., Bioactive Foods in Promoting Health, Academic Press, San Diego, 2010, pp. 525-549. http://dx.doi.org/10.1016/B978-0-12-374628-3.00035-9

[3] Y. Yasui, M. Hosokawa, T. Sahara, R. Suzuki, S. Ohgiya, H. Kohno, T. Tanaka and K. Miyashita, "Bitter Gourd Seed Fatty Acid Rich in 9c,11t,13t-Conjugated Linolenic Acid Induces Apoptosis and Up-Regulates the GADD45, p53 and PPAR[gamma] in Human Colon Cancer Caco-2 Cells,” Prostaglandins, Leukotrienes and Essential Fatty Acids, Vol. 73, No. 2, 2005, pp. 113-119. http://dx.doi.org/10.1016/j.plefa.2005.04.013

[4] N. Beloin, M. Gbeassor, K. Akpagana, J. Hudson, K. de Soussa, K. Koumaglo and J. T. Arnason, "Ethnomedicinal Uses of Momordica charantia (Cucurbitaceae) in Togo and Relation to Its Phytochemistry and Biological Activity," Journal of Ethnopharmacology, Vol. 96, No. 1-2, 2005, pp. 49-55. http://dx.doi.org/10.1016/j.jep.2004.08.009

[5] C. Hsu, T.-H. Tsai, Y.-Y. Li, W.-H. Wu, C.-J. Huang and P.-J. Tsai, "Wild bitter melon (Momordica charantia Linn. var. abbreviata Ser.) Extract and Its Bioactive Components Suppress Propionibacterium acnes-Induced Inflammation,” Food Chemistry, Vol. 135, No. 3, 2012, pp. 976984. http://dx.doi.org/10.1016/j.foodchem.2012.05.045

[6] P. V. Nerurkar, Y. K. Lee and V. R. Nerurkar, "Momordica charantia (Bitter Melon) Inhibits Primary Human Adipocyte Differentiation by Modulating Adipogenic Genes,” BMC Complementary and Alternative Medicine, Vol. 10, No. 1, 2010, p. 34.

http://dx.doi.org/10.1186/1472-6882-10-34

[7] J.-Y. Lin and C.-Y. Tang, "Determination of Total Phenolic and Flavonoid Contents in Selected Fruits and Vegetables, as Well as Their Stimulatory Effects on Mouse Splenocyte Proliferation,” Food Chemistry, Vol. 101, No. 1, 2007, pp. $140-147$. http://dx.doi.org/10.1016/j.foodchem.2006.01.014

[8] Y. Zhu, Y. Dong, X. Qian, F. Cui, Q. Guo, X. Zhou, Y. Wang, Y. Zhang and Z. Xiong, "Effect of Superfine 
Grinding on Antidiabetic Activity of Bitter Melon Powder,” International Journal of Molecular Sciences, Vol. 13, No. 11, 2012, pp. 14203-14218. http://dx.doi.org/10.3390/ijms131114203

[9] S. P. Tan, S. E. Parks, C. E. Stathopoulos and P. D. Roach, "Greenhouse-Grown Bitter Melon: Production and Quality Characteristics," Journal of the Science of Food and Agriculture, 2013, in Press. http://dx.doi.org/10.1002/jsfa.6509

[10] R. Horax, N. Hettiarachchy and S. Islam, "Total Phenolic Contents and Phenolic Acid Constituents in 4 Varieties of Bitter Melons (Momordica charantia) and Antioxidant Activities of their Extracts," Journal of Food Science, Vol. 70, No. 4, 2005, pp. C275-C280. http://dx.doi.org/10.1111/j.1365-2621.2005.tb07173.x

[11] S. J. Wu and L. T. Ng, “Antioxidant and Free Radical Scavenging Activities of Wild Bitter Melon (Momordica charantia Linn. var. Abbreviata Ser.) in Taiwan," LWTFood Science and Technology, Vol. 41, No. 2, 2008, pp. 323-330. http://dx.doi.org/10.1016/j.lwt.2007.03.003

[12] M. J. Ko, C. I. Cheigh and M. S. Chung, "Relationship Analysis between Flavonoids Structure and Subcritical Water Extraction (SWE)," Food Chemistry, Vol. 143, 2014, pp. 147-155. http://dx.doi.org/10.1016/j.foodchem.2013.07.104

[13] A. Marston and K. Hostettmann, "Separation and Quantification of Flavonoids," In: O.M. Andersen and K.R. Markham, Eds., Flavonoids: Chemistry, Biochemistry and Applications, CRC Press, USA, 2005, pp. 1-36. http://dx.doi.org/10.1201/9781420039443.ch1

[14] J. F. Shao, H. T. Jin, H. W. Zhu and J. T. Liu, “Optimization of Parameters for Ethanol Extraction of Flavone Glycosides from Ginkgo Cell and Antioxidant Activity in Vitro," Zhongguo Kuangye Daxue Xuebao/Journal of China University of Mining and Technology, Vol. 42, No. 4, 2013, pp. 663-669.

[15] A. Dalar, M. Türker, D. Zabaras and I. Konczak, "Phenolic Composition, Antioxidant and Enzyme Inhibitory Activities of Eryngium Bornmuelleri Leaf,” Plant Foods for Human Nutrition, 2013, pp. 1-7. http://dx.doi.org/10.1007/s11130-013-0393-6

[16] M. A. Hossain, K. A. S. Al-Raqmi, Z. H. Al-Mijizy, A. M. Weli and Q. Al-Riyami, "Study of Total Phenol, Flavonoids Contents and Phytochemical Screening of Various Leaves Crude Extracts of Locally Grown Thymus vulgaris," Asian Pacific Journal of Tropical Biomedicine, Vol. 3, No. 9, 2013, pp. 705-710. http://dx.doi.org/10.1016/S2221-1691(13)60142-2

[17] B. Shan, J. H. Xie, J. H. Zhu and Y. Peng, "Ethanol Modified Supercritical Carbon Dioxide Extraction of Flavonoids from Momordica charantia L. and Its Antioxidant Activity," Food and Bioproducts Processing, Vol. 90, No. 3, 2012, pp. 579-587. http://dx.doi.org/10.1016/j.fbp.2011.09.004

[18] O. Kenny, T. J. Smyth, C. M. Hewage and N. P. Brunton, “Antioxidant Properties and Quantitative UPLC-MS Analysis of Phenolic Compounds from Extracts of Fenugreek (Trigonella foenum-Graecum) Seeds and Bitter Melon (Momordica charantia) Fruit,” Food Chemistry,
Vol. 141, No. 4, 2013, pp. 4295-4302.

http://dx.doi.org/10.1016/j.foodchem.2013.07.016

[19] Q. V. Vuong, J. B. Golding, C. E. Stathopoulos, M. H. Nguyen and P. D. Roach, "Optimizing Conditions for the Extraction of Catechins from Green Tea Using Hot Water,” Journal of Separation Science, Vol. 34, No. 21, 2011, pp. 3099-3106. http://dx.doi.org/10.1016/j.foodchem.2013.07.016

[20] A. Cerda, M. E. Martínez, C. Soto, P. Poirrier, J. R. Perez-Correa, J. R. Vergara-Salinas and M. E. Zúñiga, “The Enhancement of Antioxidant Compounds Extracted from Thymus vulgaris Using Enzymes and the Effect of Extracting Solvent," Food Chemistry, Vol. 139, No. 1-4, 2013, pp. 138-143. http://dx.doi.org/10.1016/j.foodchem.2012.12.044

[21] Z. Wissam, B. Ghada, A. Wassim and K. Warid, "Effective Extraction of Polyphenols and Proanthocyanidins from Pomegranate's Peel," International Journal of Pharmacy and Pharmaceutical Sciences, Vol. 4, Supplement 3, 2012, pp. 675-682.

[22] L. Chebil, C. Humeau, J. Anthony, F. Dehez, J. M. Engasser and M. Ghoul, "Solubility of Flavonoids in Organic Solvents," Journal of Chemical and Engineering Data, Vol. 52, No. 5, 2007, pp. 1552-1556. http://dx.doi.org/10.1021/je7001094

[23] O. Ferreira and S. P. Pinho, "Solubility of Flavonoids in Pure Solvents," Industrial and Engineering Chemistry Research, Vol. 51, No. 18, 2012, pp. 6586-6590. http://dx.doi.org/10.1021/ie300211e

[24] J. G. Wu, J. Ge, Y. P. Zhang, Y. Yu and X. Y. Zhang, "Solubility of Genistein in Water, Methanol, Ethanol, Propan-2-Ol, 1-Butanol, and Ethyl Acetate from (280 to 333) K," Journal of Chemical and Engineering Data, Vol. 55, No. 11, 2010, pp. 5286-5288. http://dx.doi.org/10.1021/je100261w

[25] S. Tommasini, D. Raneri, R. Ficarra, M. L. Calabrò, R. Stancanelli and P. Ficarra, "Improvement in Solubility and Dissolution Rate of Flavonoids by Complexation with $\beta$-Cyclodextrin,” Journal of Pharmaceutical and Biomedical Analysis, Vol. 35, No. 2, 2004, pp. 379-387. http://dx.doi.org/10.1016/S0731-7085(03)00647-2

[26] A. Alberti, A. A. F. Zielinski, D. M. Zardo, I. M. Demiate, A. Nogueira and L. I. Mafra, "Optimisation of the Extraction of Phenolic Compounds from Apples Using Response Surface Methodology," Food Chemistry, Vol. 149, 2014, pp. 151-158. http://dx.doi.org/10.1016/j.foodchem.2013.10.086

[27] Q. Xu, Y. Shen, H. Wang, N. Zhang, S. Xu and L. Zhang, "Application of Response Surface Methodology to Optimise Extraction of Flavonoids from Fructus Sophorae," Food Chemistry, Vol. 138, No. 4, 2013, pp. 2122-2129. http://dx.doi.org/10.1016/j.foodchem.2012.11.099

[28] D. D. Gertenbach, "Solid-Liquid Extraction Technologies for Manufacturing Nutraceuticals,” In: J. Shi, G. Mazza, and M. L. Maguer, Eds., Functional Foods: Bioachemical and Processing Aspects, CRC Press, USA, 2002, pp. 332365.

[29] Q. You, X. Yin, S. Zhang and Z. Jiang, "Extraction, Purification, and Antioxidant Activities of Polysaccharides 
from Tricholoma mongolicum Imai," Carbohydrate Polymers, Vol. 99, 2014, pp. 1-10.

http://dx.doi.org/10.1016/j.carbpol.2013.07.088

[30] Q. V. Vuong, S. Hirun, P. D. Roach, M. C. Bowyer, P. A. Phillips and C. J. Scarlett, "Effect of Extraction Conditions on Total Phenolic Compounds and Antioxidant Activities of Carica papaya Leaf Aqueous Extracts," Journal of Herbal Medicine, Vol. 3, No. 3, 2013, pp. 104-111. http://dx.doi.org/10.1016/j.carbpol.2013.07.088

[31] M. Zhang, N. S. Hettiarachchy, R. Horax, P. Chen and K. F. Over, "Effect of Maturity Stages and Drying Methods on the Retention of Selected Nutrients and Phytochemicals in Bittermelon (Momordica charantia) Leaf," Journal of Food Science, Vol. 74, No. 6, 2009, pp. C441C446. 